\title{
Transport Pathway
}

National Cancer Institute

\section{Source}

National Cancer Institute. Transport Pathway. NCI Thesaurus. Code C91760.

An elaboration of the sequence of biological or biochemical events that result in the transport of molecules from one physiological space to another. 